\title{
PREVALENCE OF MALNUTRITION AMONG SCHOOL GOING CHILDREN OF UNIVERSITY CAMPUS PESHAWAR 2013
}

\author{
ZIA UR REHMAN ${ }^{1}$, MUHAMMAD ISHTIAQ ${ }^{2}$, MUHAMMAD NAEEM ${ }^{1}$, RUBEENA GUL ${ }^{1}$, \\ MUHAMMAD AMJAD ${ }^{1}$, IMRANULLAH ${ }^{1}$, BUSHRA IFTIKHAR $^{1}$ \\ 1. Department of Community Medicine, Khyber Medical College, Peshawar \\ 2. Department of Community Medicine, Pak International Medical College, Hayatabad, Peshawar
}

\begin{abstract}
BACKGROUND: School going children are one of the neglected public health sectors and thus lead to improper nutrition and are at potential risk for growth and developmental problems starting from early life, and eventually affecting their physical and mental status, so this study was conducted to highlight malnutrition problems among school going children.

OBJECTIVES: To find the prevalence of malnutrition in school going children of university campus Peshawar.

MATERIAL AND METHODS: A cross-sectional study was conducted among 400 school going children of university campus Peshawar; during April to August 2013. Two schools of male children of age four to twelve years were included while female children, migrants, and those having any pathological conditions were excluded. Weight and height were measured and body mass index calculated using standard procedures of anthropometric measurements. After that the individual BMI were categorized according to the international standards.

RESULTS: The prevalence of malnutrition in our study was $37 \%$ among 4 to 12 years school age children of university campus Peshawar. The prevalence of under nutrition was found in $30 \%$; out of which $18 \%$ were slightly underweight, $10 \%$ were moderately underweight and only $2 \%$ were severely underweight, while only $7 \%$ were overweight.

CONCLUSIONS: The prevalence of malnutrition was more (37\%) among four to twelve years school going children of University campus Peshawar and approximately $63 \%$ were normal on the measurements of BMI calculated.
\end{abstract}

-KEY WORDS: Prevalence, Malnutrition, Underweight, Children.

\section{INTRODUCTION}

According to WHO survey, prevalence of underweight is $23 \%$ worldwide and $41 \%$ in south Asia $^{(1)}$. The prevalence of moderate underweight in Pakistan is $31 \%$ and severe underweight is $13 \%$ as shown by National Nutritional Survey $(2001-2002)^{(2)}$. The World Health Organization estimates that by the year 2015 , the prevalence of malnutrition will be reduced to $17.6 \%$ globally, with 113.4 million children younger than 5 years affected as measured by low weight for age. The overwhelming majority of these children, 112.8 million, will live in developing countries with $70 \%$ of these children in Asia, particularly the south-central region, and $26 \%$ in Africa (3). Malnutrition is globally the most important risk factor for illness and death, contributing to more than half of deaths in children worldwide; child malnutrition was associated with $54 \%$ of deaths in children in developing countries in $20013^{(4)}$. In developing countries, poor perinatal conditions account for $23 \%$ of deaths in children younger than five. Malnourished women are at high risk of giving birth to low birth weight infants. Many low birth weight infants $(23 \%$ of all births) face severe short-term and long-term health consequences, such as growth failure in infancy and childhood, which increases risk of morbidity and early death ${ }^{(4,5)}$. Despite marked improvements globally in the prevalence of malnutrition, rates of under nutrition and stunting have continued to rise in Africa, from $24 \%$ to $26.8 \%$ and $47.3 \%$ to $48 \%$, respectively, since $1990^{(6)}$. 
Pakistan, having population of 164 million, with low level of socioeconomic development, human development index is 142nd in the world and $24 \%$ of the population lives below poverty line with $17 \%$ earning less than a dollar a day ${ }^{(7)}$. The health profile of Pakistan is characterized by high population growth rate, high infant mortality and child mortality rates of 78 and 97 per 100,000 respectively $^{(8)}$. At the national level, $24 \%$ of the population is under the calorie based food plus non-food poverty line and more than $41 \%$ children less than 5 are under weight for their age ${ }^{(9)}$. Knowing the importance of malnutrition prevalence; we conducted this study to find the prevalence of malnutrition and to recommend measures for its prevention.

\section{MATERIAL AND METHODS}

A cross-sectional study was conducted among school going children of university campus Peshawar. First of all, list of all schools of university campus, were constructed and then following the inclusion and exclusion criteria, female school going children were excluded and only two male schools were included by means of simple random method, and from each school 100 children were selected randomly. The sample size of 400 was calculated on the basis of WHO sample formula having $50 \%$ prevalence and $95 \%$ confidence interval with $5 \%$ precision. Male school going children were selected while a child suffering from any disease, migrants and uncooperative were excluded. 400 male children were selected and weight and height were measured and body mass index calculated and then interpreted accordingly. The weight was measured on a weight machine and the height measured using measuring tape. Before the actual data collection, a pilot study was conducted to assess the efficiency of the study questionnaire. SPSS and Microsoft Excel 2007 XP were used for data entry, processing and analysis.

\section{RESULTS \& DISCUSSION}

The study is unique in its character because it is the first ever study to find the prevalence of malnutrition in school going children of age range four to twelve years among university campus. The prevalence of BMI less than 19 were found in $30 \%$ of school going children. In our study, the prevalence of malnutrition calculated was $37 \%$ among school children whereas in a study conducted in 2004 by the District Health Office in Rawalpindi, whose sample included 1251 students studying in 45 different Madrassas in the city, showed that around $14 \%$ of school children were suffered from malnutrition (10). According to our study results, $63 \%$ of schools going children were having normal BMI as calculated. Out of $37 \%$ malnourished, $30 \%$ of schools going children were having $\mathrm{BMI}$ less than normal that is less than 19; while only $7 \%$ has BMI more than 25 . Interestingly in our study results, none of the school children were found to have BMI more than 29.

In our study the prevalence of under nutrition as of BMI less than 24 were calculated as $30 \%$ while according to WHO statistics, $45 \%$ male and $47 \%$ females are under weight in Pakistan $^{(11)}$. According to National Nutritional Survey (2001-2002), the prevalence of mild under nutrition was $24 \%$, prevalence of moderate under nutrition was $31 \%$ in Pakistan and severe under nutrition was $13 \%{ }^{(12)}$. In our study, $7 \%$ were overweight having BMI between 25 to 29.9; and thus none of the children going children were obese as shown in Table NO: 1 \& Graph No 1.

Graph No 1. Percentage of Different Catagories of Malnutrition Among $n=400$ School Going Children of University Campus Peshawar

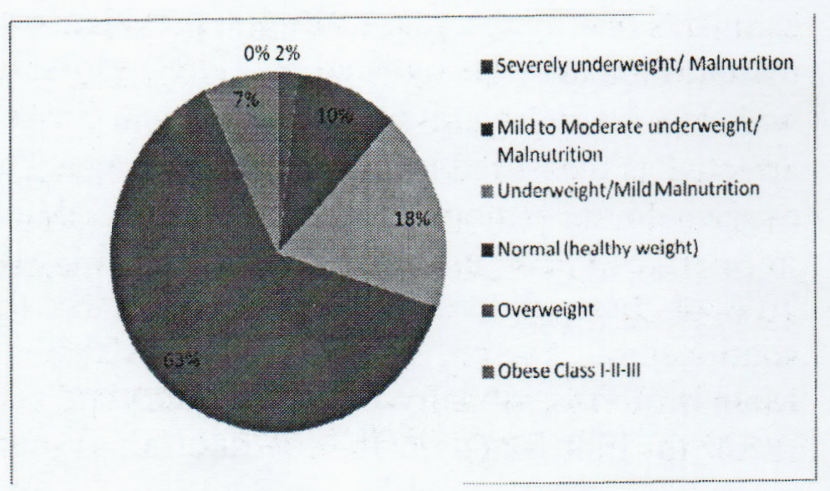


In our study, $18 \%$ were underweight having BMI between 19-23.9, 10\% were mild to moderate underweight having BMI 15-15.9; and only $2 \%$ were severely underweight having BMI less than 15, while in a study the prevalence of underweight turned out to be $17 \%$ in study conducted at Rana Liaquat Government College of home-economics, Karachi ${ }^{(13)}$. Similarly in South Asia according to WHO statistics the prevalence of moderate and severe under nutrition was $46 \%$ and $22 \%$ respectively ${ }^{(11)}$. According to National Nutritional survey (2001 - 2002), the prevalence of moderate stunting in Pakistan is $37 \%$ and prevalence of severe stunting is $18 \%^{(12)}$. In the above study, the wasting in students was $14 \%$ while according to National Nutritional survey; $13 \%$ of NCHC reference population suffers from moderate under nutrition was about $3 \%{ }^{(12)}$. In another study of Ijaz et al. the under nutrition prevalence was $32.7 \%$ in urban students and $32.7 \%$ in rural students while in our study $30 \%$ of school going children were under nutrients ${ }^{11}$. In Our study, the prevalence of under nutrition was less but in accordance to the prevalence level in urban setup like university campus Peshawar.

\section{CONCLUSION \& RECOMMENDATIONS}

It was concluded that frequency of malnutrition both under nutrition and over nutrition was prevalent among school going children of age ranges four to twelve years of university campus Peshawar. Our study results are closed to the national research studies conducted and showed similar and approximate figures in school going children. Thus it is recommended that the children especially the preschool and school going should be given due consideration and the responsibility of parents and teachers be increased regarding periodically monitoring of school going young children. Apart from these the concerned institutions should conduct medical examination of all children to prevent unnecessary morbidity and mortality associated with malnutrition.

Table No 1.Frequency of Different Catagories of Malnutrition Among $n=400$ School
Going Children of University Campus Peshawar

\begin{tabular}{|l|c|c|}
\hline Category of Malnutrition & $\begin{array}{c}\text { BMI } \\
\text { Range } \\
\mathbf{k g} / \mathbf{m}^{2}\end{array}$ & Frequency \\
\hline $\begin{array}{l}\text { Severely underweight/ } \\
\text { Malnutrition }\end{array}$ & $<15.00$ & 12 \\
\hline $\begin{array}{l}\text { Mild to Moderate } \\
\text { underweight/Malnutrition }\end{array}$ & $\begin{array}{c}15.00- \\
15.99\end{array}$ & 60 \\
\hline Underweight/Mild & $\begin{array}{c}16.00- \\
18.49\end{array}$ & 108 \\
Malnutrition & $\begin{array}{c}18.50- \\
24.99\end{array}$ & 378 \\
\hline Normal (healthy weight) & $25.00-$ & 42 \\
\hline Overweight & $>30.99$ & 0 \\
\hline Obese Class I-II-III & 30.00 & 42 \\
\hline
\end{tabular}

\section{REFERENCES}

1. The prevalence of under nutrition, stunting and wasting by country; WHO statistics.

2. National Nutrition Survey 2001-02, Final report (Draft), pp. 41-2.

3. Blossner, Monika, de Onis, Mercedes. Environmental Burden of Disease Series. Malnutrition: quantifying the health impact atnational and local levels. Geneva, Switzerland: World Health Organization; 2005.

4. Hendricks KM, Duggan C, Gallagher L, et al. Malnutrition in hospitalized pediatric patients. Current prevalence. Arch Pediatr Adolesc Med. Oct 2005;149(10):1118-22.

5. Mendez MA, Adair LS. Severity and timing of stunting in the first two years of life affect performance on cognitive tests in late childhood. J Nutr. Aug 2001;129(8):1555-62.

6. World Health Organization. Malnutrition-The Global Picture, 2008.

7. Heywood AH, Marshall T, Heywood PF. Motor development and nutritional status of young children in Madang, Papua New Guinea. P N G Med J. Jun 2002;34(2):109-16.

8. Martorell R, Rivera J, Kaplowitz H, Pollitt E. Longterm consequences of growth retardation during early childhood. In: Hernandez M, Argente J. Human growth:basic and clinical aspects. Amsterdam: Elsevier Science Publishers; 2004:143-149.

9. Kumar, V., Cotran, R.S., Robbins, S.L. Environmental Diseases. In: Robbins Basic Pathology. $7^{\text {th }}$ Ed. Philadelphia: W.B. Saunders, 2003., pp: 303.

10. World Health Organization. Body Mass Index and Obesity. Geneva, 2009..

11. Recommended Daily Intakes (RDI). American Dietetic Association. Developed by the Chicago 
Dietetic Association and The South Suburban Dietetic Association. Manual of Clinical Dietetics, $5^{\text {th }}$ Ed., 2008.pp: 3-23.

12. Williams, S.R. Energy balance and weight management in: Essential of Nutrition and Diet Therapy. $7^{\text {th }}$ E.D., 2005.pp: 85-106.

13. Ferro-Luzzi. Classification of malnutrition according to Body Mass Index. Food Nutrition.Bull Sep 2002; 25 (2 Suppl): 56-61.
CORRESPONDING ADDRESS:

Dr Muhammad Ishtiaq

Assistant Professor

Department of Community Medicine

Pak International Medical College

Plot-2, Sector B-2, Phase-5, Hayatabad Peshawar

Contact No: 0334-9121822, 091-5892738 (127)

Email address: drishtiaq250@yahoo.com 